\title{
An incidental finding of uterine adenolipoleiomyoma in an endometrial polyp: A case report
}

\author{
Edwin E Coello Gordon* Evelyn Carolina Polanco Jacome \\ Departamento de Anatomía Patológica Hospital San Francisco de Quito - IESS Ecuador
}

Received: June 4, 2020

Accepted: July 15, 2020

Online Published: August 19, 2020

DOI: $10.5430 /$ crcp.v7n1p15

URL: https://doi.org/10.5430/crcp.v7n1p15

\begin{abstract}
Uterine adenolipoleiomyoma is a benign hamartomatous lesion of controversial origin, with descriptions of exceptional cases published in the literature. We present the case of a 65 -year-old female patient who presented an adenolipoleiomyoma in an endometrial polyp incidentally found during a hysterectomy performed for a cervical lesion. The incidental finding consisted of müllerian type glands, smooth muscle and mature adipose tissue.
\end{abstract}

Key Words: Adenolipoleiomyoma, Hamartoma, Endometrial polyp

\section{INTRODUCTION}

Uterine adenolipoleiomyoma is an extremely rare variant of lipoleiomyoma with epithelial components. ${ }^{[1]}$ In the literature, there are only five reported cases. ${ }^{[1-5]}$ This lesion has been described in perimenopausal patients with a history of vaginal bleeding and pelvic pain. In two reported cases these lesions were found in the context of endometrial polyps, ${ }^{[1,6]}$ but none of the reported cases was presented as an incidental finding. Our report represents the first case presenting as an endometrial polyp found incidentally in a postmenopausal women. Due to the controversial nature of the entity and the low number of publications, which includes a report of aggressive behavior ${ }^{[4]}$ we believe that publicizing our findings in this case will contribute to the literature.

\section{CASE PRESentation}

This case is of a 65 -year-old female patient with a history of a rectovaginal fistula for 30 years. The patient's gynecoobstetric history highlights regular menstrual cycles of nor- mal duration and flow until 15 years ago, an active sexual life beginning at 24 years of age, 4 gestations with normal deliveries, and no history of vaginal bleeding or pelvic pain. Pelvic ultrasound (US) studies revealed two hyperechogenic images, the first one, measuring $0.6 \mathrm{~cm}$ and located at the uterine fundus, which was presumptive of polyp; and the second one, measuring $3.0 \mathrm{~cm} \times 2.5 \mathrm{~cm}$, which was echographically compatible with intramural myoma.

Seven months prior to this presentation, a cytological diagnosis of Low grade squamous intraepitelial lesion (LSIL) was made with a molecular Human Papillomavirus (HPV) test negative for 16 and 18 subtypes and other positive highrisk subtypes. The biopsy revealed an in situ squamous cell carcinoma, after which the patient underwent a vaginal hysterectomy plus bilateral salpingectomy.

Macroscopic examination revealed a $6.0 \mathrm{~cm} \times 5.5 \mathrm{~cm} \times$ $2.0 \mathrm{~cm}$ uterus with a rough dark brown exocervix. Once the specimen was opened, a firm, whitish-colored $1.5 \mathrm{~cm} \times 1.0$ $\mathrm{cm}$ polypoid lesion was observed in the uterine fundus.

\footnotetext{
* Correspondence: Edwin E Coello Gordon; Email: edutropi@ hotmail.com; Address: Departamento de Anatomía Patológica Hospital San Francisco de Quito - IESS Ecuador.
} 

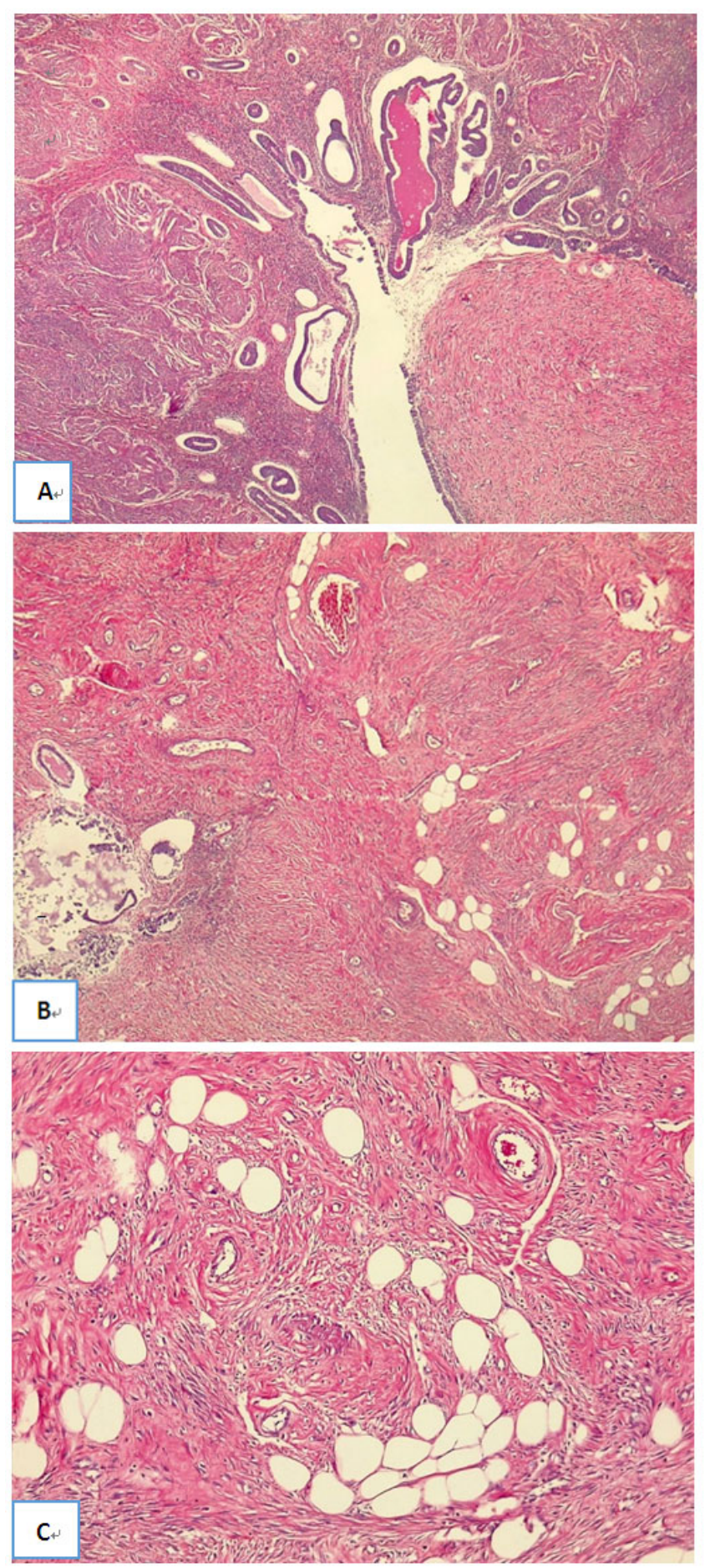

Figure 1. Microscopic examination in hematoxylin and eosin (H\&E) demonstrates A-B) Dilated endometrial glands with proteinaceous content in a fund composed of bands of smooth muscle tissue and little mature adipose tissue, 4x. C) Mature adipose tissue, mixed with smooth muscle bands, $10 \mathrm{x}$

Additionally, a firm, white, and swirled $2.0 \mathrm{~cm} \times 1.5 \mathrm{~cm}$ in- tramural nodule was found. Upon microscopic examination, the polypoid-looking lesion showed simple cystic endometrial glands, some that had cysts with intraluminal secretion in a background consisting of intertwined bundles of smooth muscle fibers, mature adipose tissue and blood vessels with thickened walls (see Figure 1). The intramural lesion showed histomorphological characteristics of a conventional leiomyoma. In addition, microscopic examination confirmed the presence of high grade cervical intraepithelial Lesion CIN III/carcinoma in situ.

Based on the histomorphological findings, the polypoid lesion was diagnosed as adenolipoleiomyoma in an endometrial polyp. Because the patient underwent a hysterectomy, there was no additional clinical follow-up.

\section{DISCUSSION}

Adenolipoleiomyoma or adenomyomatous hamartoma is an extremely unusual type of benign neoplasm in the female genital tract. ${ }^{[1-5]}$ This type of lesion is located in the uterus of perimenopausal women and presents clinically in the form of irregular vaginal bleeding and pelvic pain. ${ }^{[1,6]}$

Macroscopically, adenolipoleiomyomas can present as endometrial polyps or as intraluminal or intramural masses. Adenolipoleiomyomas arising from endometrial polyps vary from 2.5 to $7.0 \mathrm{~cm}$ in length, are whitish-yellowish in appearance, and are fibrous in consistency. ${ }^{[1,3]}$

Intraluminal or intramural lesions are well delimited and are not encapsulated. They range in size from $1.5 \mathrm{~cm}$ to 4.3 $\mathrm{cm}$ and are grayish-white in appearance with yellowish areas. Larger intramural lesions may present areas of myxoid degeneration. ${ }^{[4]}$

Upon microscopy, adenolipoleiomyomas are well-defined, non-infiltrative lesions made up of mullerian-type glandular structures on a background of smooth muscle bundles and islands of mature adipocytes. They show no microscopic evidence of increased mitotic activity, cellular atypia, or necrosis. With the information available currently it is thought that it corresponds to a benign hamartomatous lesion. ${ }^{[1,2]}$ However authors like Shaco et al. ${ }^{[4]}$ and Mc Cluggage et al. ${ }^{[2]}$ consider adequate follow-up of these patients to confirm this presumption. Other authors such as Yavuz et al., ${ }^{[6]}$ believe that the adenolipoleiomyoma is a variant of benign mixed mullerian tumors.

In the present case, the presence of mature components of mullerian glandular tissue, smooth muscle and adipose metaplasia confirms the hamartomatous nature of this lesion. ${ }^{[3]}$ In addition, the presence of thickened blood vessels with the glands' cystic appearance is associated with the characteris- 
tics of an endometrial polyp.

In the differential diagnosis, several benign stromal lesions that affect the uterine body are considered; ${ }^{[3]}$ polypoid atypical adenomyoma is a lesion characterized by the presence of endometrial glands of complex architecture with cytological atypia and extensive squamous metaplasia. ${ }^{[1]}$ These last characteristics are absent in the present case.

The presence of adenomyosis in a lipoleiomyoma is a good differential diagnosis; ${ }^{[1]}$ however, in the present case, there is a proliferation of smooth muscle fibers with a swirling pattern, the lesion is very well circumscribed and the foci of adenomyosis in the uterine wall are not identified. ${ }^{[2]}$ Another possible differential diagnosis would be uterine angiomyolipoma, which is an extremely rare benign tumor composed of smooth muscle tissue, thickened vascular walls, and mature adipocytes. This lesion differs from adenolipoleiomyoma in that it is an encapsulated, multiloculated lesion that lacks glandular structures at the microscopic level. ${ }^{[7]}$

\section{Conclusion}

Adenolipoleiomyoma is a lesion of a still controversial nature and etiology. It is extremely infrequent, with very few cases published in the literature.

Microscopically, adenolipoleiomyoma is a hamartomatous lesion made up of mullerian glandular elements, smooth muscle and mature adipose tissue. Necrosis or increased mitotic activity were not found in any of the cases currently reported; these soft histological characteristics suggest its benign behavior. Given the history of extensive local recurrence in one of the published reports, ${ }^{[4]}$ more data is required to accurately define its behavior. Our case is interesting because it is the only one reported in a postmenopausal woman that arose from an endometrial polyp incidentally found in the uterine fundus.

\section{CONFlicts OF InTEREST Disclosure}

We declare that we have no conflict interests.

\section{REFERENCES}

[1] Payne, F, Rollason, TP, Sivridis E. Adenomyolipoma of the endometrium-a. Histopathology. 1992;20:357-9. PMid:1577415. https://doi.org/10.1111/j.1365-2559.1992.tb00995.x

[2] Mccluggage WG, Hamal P, Traub AI, Walsh MY. Case Report Uterine Adenolipoleiomyoma: A Rare Hamartomatous Lesion. Int J Gynecol Pathol. 2000;(19):183-5. PMid:10782418. https ://doi. org/10.1097/00004347-200004000-00015

[3] Catteau X, Anaf V, Noël J, Presentation C. Case Report Adenolipoleiomyoma Polyp of the Uterus: A Case Report and Review of the Literature. 2018;2018:1-4. PMid:30258662. https: //doi.org/10.1155/2018/5704382

[4] Shaco-levy R, Piura B. Case Report Uterine Adenolipoleiomyoma: A Tumor With Potential of Aggressive Behavior. Int J Gynecol Pathol.
2008;(27):252-7. PMid:18317215. https ://doi.org/10.1097/ PGP.0b013e3181569a37

[5] Selvarajan S, Potala P, Tan HK, Mantoo S. Adenolipoleiomyoma of the cervix - a unique cervical polyp: a case report and review of literature. Pathology [Internet]. 2017;49:S125. https://doi .org/ $10.1016 / j$. pathol .2016 .09 .008

[6] Ilhan R, Yavuz E, Iplikçi A, Tuzlalı S. Hamartomatous endocervical polyp with heterologous mesenchymal tissue. Pathol Int. 2001;(51):305-7. PMid:11350615. https://doi.org/10.1046/ j.1440-1827.2001.01194.x

[7] Hong J, Heo G, Kwak JJ, Chung S. A case report of angioleiomyoma of uterus. Obstet Gynecol Sci. 2017;60(5):494-7. PMid:28989930. https://doi.org/10.5468/ogs.2017.60.5.494 